\title{
Hydrolytic decomposition of glycosides in aqueous acids
}

\author{
Satu Mikkola*, a and Mikko Oivanen ${ }^{b}$ \\ ${ }^{a}$ Department of Chemistry, FIN-20014 University of Turku, Finland \\ ${ }^{b}$ Department of Chemistry, P.O.Box 55 (A.I.Virtanen Sq. 1), FIN-00014 University of Helsinki, \\ Finland \\ E-mail: satu.mikkola@utu.fi
}

\section{Dedicated to Prof. Harri Lönnberg on the occasion of his $60^{\text {th }}$ birthday}

\begin{abstract}
A review is presented that collects the experimental results published on the acid catalyzed hydrolysis of alkyl and aryl pyranosides and furanosides over the last three decades. In aqueous acid, alkyl furanosides and pyranosides are hydrolysed via an oxocarbenium intermediate, which may be formed from the protonated substrate either by an exocyclic or endocyclic $\mathrm{C}-\mathrm{O}$ bond cleavage. Both mechanisms lead eventually to the same products. Various methods have been used to distinguish between the pathways, and a lot of evidence exists to show that different pathways are followed depending on the structure of both the glycon moiety and the departing alcohol.
\end{abstract}

Keywords: Alkyl glycosides, hydrolysis, oxocarbenium ion, endocyclic, exocyclic

\section{Table of Contents}

1. Introduction

2. Acidic Hydrolysis of Alkyl and Aryl Furanosides

3. Acidic Hydrolysis of Alkyl and Aryl Pyranosides

4. Discussion

5. References

\section{Introduction}

The earliest reports on the mechanisms of the hydrolytic cleavage of glycosides were published in the beginning of the $20^{\text {th }}$ century by Armstrong and Fischer. ${ }^{1}$ Since then, the interest in carbohydrate chemistry has continued and never ceased completely. Still, after intensive research, the mechanistic details of hydrolytic cleavage of glycosides continue to form a 
challenge for chemists. Even the simplest carbohydrate molecules allow great variation of possible reaction pathways.

The hydrolytic mechanisms of glycosides have been studied to understand the chemistry and reactivity of the important biomolecules and their analogs, but also in order to construct a solid base of knowledge for the numerous applications of carbohydrates and oligosaccharides. The topics of applications involve, for instance, solid-phase synthesis of carbohydrates and oligosaccharides, development of therapeutically active carbohydrates, development of artificial glycosidases and mechanistic studies on glycoside modifying enzymes and enzyme mimics.

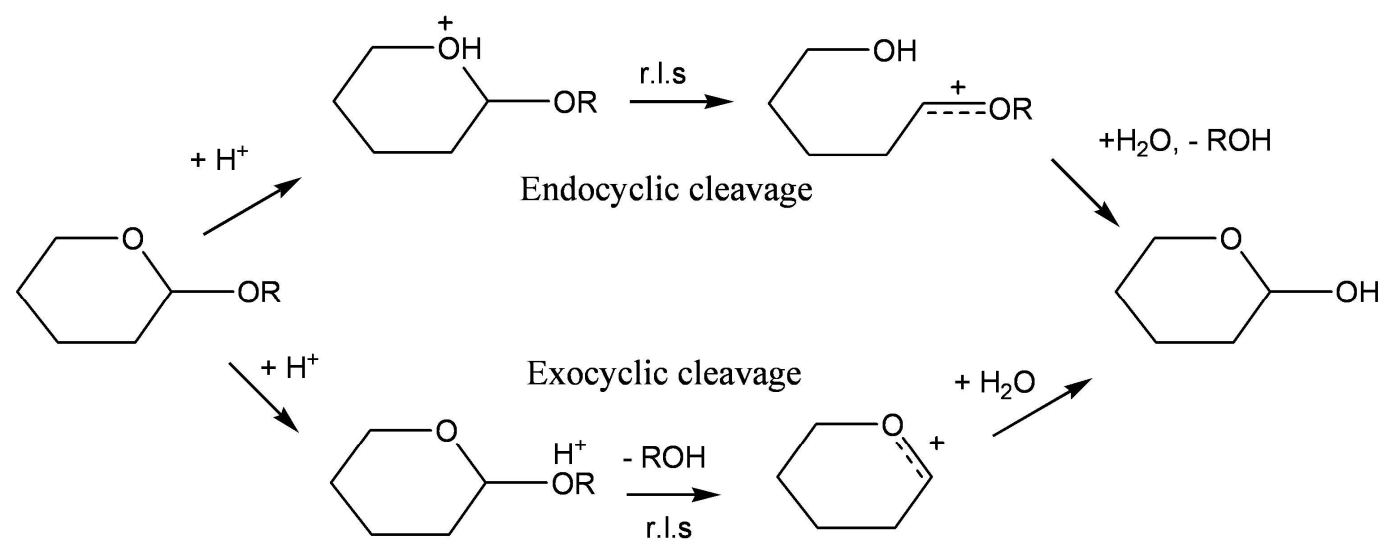

Scheme 1. The two mechanisms of acid catalysed cleavage of glycosides (r.l.s. = rate-limiting step).

The most central process in the chemistry of carbohydrates is the nucleophilic displacement at the glycosidic (anomeric) carbon, which also may involve various reaction pathways. For example, for acid catalyzed cleavage of alkyl and aryl glycosides, two different mechanisms have been presented, as shown schematically in Scheme 1. The reactions may be called exocyclic and endocyclic, referring to the site of the $\mathrm{C}-\mathrm{O}$ bond cleavage that precedes the formation of the oxocarbenium intermediate. A number of mechanistic studies have been carried out in order to determine which one of the mechanisms predominates in different cases. Both mechanisms lead eventually to the same products and various methods have been used to distinguish between the pathways. A lot of evidence exists to show that different pathways are followed depending on the structure of both the glycon moiety and the departing alcohol. In the following review we wish to collect and discuss the experimental results published on the acid catalyzed hydrolysis of alkyl and aryl pyranosides and furanosides over the last three decades. In 1970's Lönnberg and his coworkers carried out extensive kinetic studies on the hydrolysis of aldofuranosides. ${ }^{2,3}$ The effect of the structure of the glycon and aglycon, a comparison of the leaving group effects to those observed with known acetal analogs, kinetic activation parameters, solvent isotope effects and effects of solvent mixtures were studied to evaluate the reaction mechanism. In the following work of the group, the applicability of the same kinetic methods 
was established in distinguishing the pathways of the hydrolysis of the $N$-glycosidic linkage of numerous nucleoside analogs, ${ }^{4}$ and the work formed the basis for innovative contributions in nucleoside and nucleotide chemistry.

Meanwhile, the mechanisms of $O$-glycoside hydrolysis have been studied by several groups, the applied methods including, e. g., determining the isotope effect values, trapping the reaction intermediates, and computational methods. ${ }^{5-8}$

The chemical cleavage of pyranosides is believed to follow predominantly the exocyclic pathway. ${ }^{5}$ In the case of furanosides, the endocyclic pathway is more prominent, although within both series the proportion of the competing reactions depends on the structure of the glycoside and reaction conditions. ${ }^{2}$ The hydrolytic studies have often been motivated by the idea that understanding chemical reactivity also helps in describing the mechanisms and factors utilized by the glycoside degrading enzymes. However, it has also frequently been claimed that the chemical hydrolysis as such is not a fully relevant model for most enzymes, since covalent or coordinated transition states may be involved in many cases. ${ }^{9,10}$ For instance, while the glycosidase catalyzed hydrolysis of alkyl glycosides is shown to proceed through a transition state showing some character of cyclic oxocarbenium ion, this species is formed as coordinated to the carboxyl functions of the enzyme active site. ${ }^{9}$ Coordination is also required to determine the stereospecificity of the process.

\section{Acidic Hydrolysis of Alkyl and Aryl Furanosides}

A vast body of kinetic evidence suggests that the hydrolysis of furanosides can proceed either via the endocyclic or the exocyclic pathway depending on the structure of the substrate. ${ }^{2}$ The effect of the aglycon group polarity, the effect of the polarity of reaction medium, a change in the sense of activation entropies and different isotope effect values have all been taken as an indication of a gradual change in the mechanism as the structure of the substrate changes.

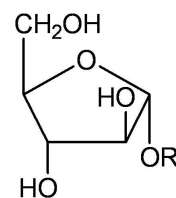

1a

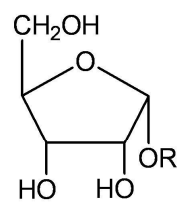

3a

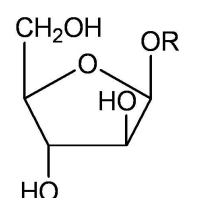

$1 \mathbf{b}$

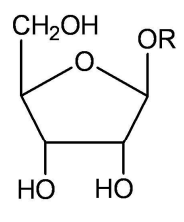

$3 \mathbf{b}$

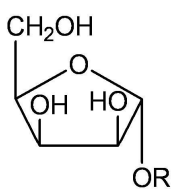

2

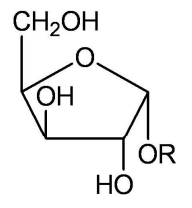

$4 a$

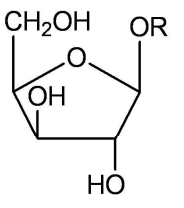

4b

Figure 1 


\section{The effect of the aglycon group polarity}

As can be seen from the second-order rate constants collected in Table 1, the sensitivity to the aglycon polarity is different with different substrates. ${ }^{2}$ The rate of the acid catalysed hydrolysis of ribofuranosides $(\mathbf{3 a}, \mathbf{b})$, for example, is quite sensitive to the polarity of the aglycon group, the reactivity decreasing constantly as the polarity of the leaving group increases. In contrast, with some glycosides the decrease levels off and substrates with more polar aglycon groups are cleaved approximately at the same rate. This behaviour is seen with phenyl aglycons, but is observed also with some alkyl furanosides, for example in $\alpha$-D-arabinofuranoside (1a) and $\alpha$-Dlyxofuranoside (2) series, where all other substrates but the isopropyl furanoside, react at approximately the same rate.

Table 1. Kinetic data obtained for the acid catalysed hydrolysis of alkyl and aryl aldofuranosides in $0.10 \mathrm{M} \mathrm{HClO}_{4}$. Structures are shown in Fig.1. Data taken from ref. 2.

\begin{tabular}{lllll}
\hline Glycoside & Aglycon & $k_{2} / 10^{-3} \mathrm{~mol}^{-1} \mathrm{~s}^{-1, a}$ & $\Delta \mathrm{S}^{\ddagger} / \mathrm{JK}^{-1} \mathrm{~mol}^{-1, b}$ & $\Delta \mathrm{H}^{\ddagger} / \mathrm{KJol}^{-1, c}$ \\
\hline$\alpha$-D-Arabinosides 1a & Isopropyl & $2.34 \pm 0.15$ & $-15 \pm 8$ & 93.6 \\
& Ethyl & $0.715 \pm 0.052$ & $15 \pm 9$ & 107.1 \\
& Methyl & $0.386 \pm 0.017$ & $7 \pm 8$ & 106.0 \\
& 2-Methoxyethyl & $0.272 \pm 0.036$ & $24+16$ & 112.7 \\
$\beta$-D-Arabinoside 1b & 2-Chloroethyl & $0.332 \pm 0.007$ & $22 \pm 3$ & 111.4 \\
& Isopropyl & $24.2 \pm 0.3$ & $-19 \pm 5$ & 85.8 \\
& Ethyl & $5.49 \pm 0.14$ & $-1 \pm 6$ & 97.1 \\
& Methyl & $1.735 \pm 0.046$ & $-13 \pm 11$ & 95.1 \\
& 2-Methoxyethyl & $0.743 \pm 0.056$ & $14 \pm 10$ & 106.4 \\
$\alpha$-D-Lyxosides 2 & & & & \\
& Isopropyl & $11.89 \pm 0.42$ & $-1 \pm 9$ & 93.7 \\
& Methyl & $2.05 \pm 0.02$ & $31 \pm 4$ & 109.2 \\
& 2-Methoxyethyl & $2.29 \pm 0.04$ & $50 \pm 4$ & 115.3 \\
$\alpha$-D-Ribosides 3a & & & & \\
& Isopropyl & $36.8 \pm 0.9$ & $-17 \pm 7$ & 85.4 \\
& Methyl & $4.15 \pm 0.13$ & $-12 \pm 10$ & 93.2 \\
& 2-Methoxyethyl & $2.29 \pm 0.085$ & $13 \pm 7$ & 103.7 \\
& & & & \\
$\beta$-D-Ribosides 3b & Isopropyl & $59.5 \pm 2.4$ & $-23 \pm 9$ & 82.1 \\
& Methyl & $8.16 \pm 0.07$ & $-29 \pm 2$ & 85.4 \\
& Methoxyethyl & $2.84 \pm 0.11$ & $-20 \pm 9$ & 93.8 \\
& Chloroethyl & $1.189 \pm 0.084$ & $-14 \pm 10$ & 95.9 \\
& & & & \\
\hline
\end{tabular}


Table 1.Continued

\begin{tabular}{lllll}
\hline Glycoside & Aglycon & $k_{2} / 10^{-3} \mathrm{~mol}^{-1} \mathrm{~s}^{-1, a}$ & $\Delta \mathrm{S}^{\ddagger} / \mathrm{JK}^{-1} \mathrm{~mol}^{-1, b}$ & $\Delta \mathrm{H}^{\ddagger} / \mathrm{kJml}^{-1, c}$ \\
\hline$\alpha$-D-Xylosides 4a & Isopropyl & $87 \pm 6$ & $-31 \pm 9$ & 78.5 \\
& Ethyl & $35.9 \pm 0.6$ & $-25 \pm 5$ & 82.9 \\
& Methyl & $11.29 \pm 0.26$ & $-20 \pm 5$ & 87.5 \\
& 2-Methoxyethyl & $3.61 \pm 0.18$ & $-6 \pm 12$ & 95.5 \\
$\beta$-D-Xylosides 4b & & & \\
& Isopropyl & $66.5 \pm 4.6$ & $-26 \pm 6$ & 80.6 \\
& Ethyl & $24.7 \pm 0.8$ & $-27 \pm 4$ & 83.0 \\
& Methyl & $8.00 \pm 0.09$ & $-15 \pm 4$ & 90.3 \\
& 2-Methoxyethyl & $2.25 \pm 0.04$ & $-11 \pm 3$ & 95.1 \\
& 2-Chloroethyl & $0.761 \pm 0.043$ & $11 \pm 7$ & 105.3 \\
& 2,2,2-Trichloroethyl & $1.185 \pm 0.039$ & $30.9 \pm 9$ & 110.3 \\
& 4-Methylphenyl & $3.17 \pm 0.17$ & $8 \pm 12$ & 100.5 \\
& Phenyl & $3.88 \pm 0.19$ & $25 \pm 9$ & 105.6 \\
& 4-Chlorophenyl & $2.99 \pm 0.09$ & $7 \pm 7$ & 100.4 \\
& 4-Acetylphenyl & $4.13 \pm 0.13$ & $15 \pm 8$ & 101.9 \\
\hline
\end{tabular}

${ }^{a}$ at $333.15 \mathrm{~K} .{ }^{b} 298.15 \mathrm{~K} .{ }^{c}$ Calculated from data in ref. 2. Values refer to $298.15 \mathrm{~K}$.

The insensitivity of the reaction rate on the polarity of the aglycon has been attributed to the exocyclic reaction, where the leaving group oxygen is protonated in a pre-equilibrium and the protonated leaving group departs in the rate-determining step of the reaction. ${ }^{2}$ Increasing polarity affects the rate in two ways that compensate each other: leaving group property is improved, but protonation becomes less favoured. Therefore the net effect is very modest. Clear inverse effect of the polarity, in contrast, refers to the endocyclic reaction, where the protonation takes place at the ring oxygen and an acyclic oxocarbenium ion is formed as a result of the rate-limiting ringopening by rupture of the $\mathrm{C}-\mathrm{O}$-bond between the protonated oxygen and anomeric carbon. In this case polarity of the aglycon has a less significant effect on the protonation and, on the other hand, electron donation from the aglycon stabilizes the acyclic oxocarbenium intermediate. The reaction is hence enhanced, and the rate is the faster the more electropositive the aglycon is.

\section{Activation entropies}

Activation entropies for the acid catalysed hydrolysis of aldofuranosides have also been collected in Table 1. It can be seen that there is a clear trend: the hydrolysis of the most reactive substrates with least polar aglycons is characterized by negative activation entropy, whereas activation entropies of the hydrolysis of substrates with aryl groups or polar alkyl groups are positive. Similar results have been reported also by Isaacs et al.: ${ }^{11}$ values of activation entropy of the hydrolysis of methyl furanosides are negative, whereas values for the hydrolysis of corresponding phenyl glycosides are positive. Isaacs et al. ${ }^{11}$ have taken negative activation 
entropy values, accompanied by negative values of activation volume, as an indication of a bimolecular reaction mechanism. Thus, the authors favour an A-2 type mechanism for the reason that the negative activation entropy values are most typically characteristic for this mechanism, whereas with the endocyclic reaction the negative activation entropies are less evident.

Considering the clear correlation between the sense of the values of activation entropy and the effect of the aglycon polarity, the negative activation entropies could also be attributed to ring-opening reaction without a need of evoking nucleophilic assistance in the rate-limiting step of the reaction. ${ }^{2}$ Consistent with this suggestion, negative activation entropies have been reported for the cleavage of related compounds that are known to react via a unimolecular opening of a five-membered ring. This is the case for example with acid-catalysed hydrolysis of 1,3dioxolanes. ${ }^{12}$ Positive values of activation entropy can be easily attributed to a unimolecular reaction, where the leaving group departs at the rate-limiting step of the reaction.

\section{Solvent effects}

The effect of increasing DMSO concentration supports the suggested unimolecular reaction mechanism, which proceeds without the solvent being involved in the rate-limiting step. The rate of the hydrolysis decreases as the DMSO content increases from 0 to $30 \%$, which was found comparable trend to that observed to be characteristic of unimolecular hydrolysis reactions of various acetals. ${ }^{13}$ At a higher DMSO content, the rate of the hydrolysis of substrates with aryl or polar alkyl aglycons increases slightly, whereas rate decrease is observed with substrates with less polar aglycons. ${ }^{2}$ This observation provides further evidence for the mechanistic difference between these two classes of compounds

\section{Isotope effects}

Isotope effect experiments also confirm the mechanistic difference between different furanosides. ${ }^{6,7}$ Ring oxygen ${ }^{18} \mathrm{O}$ isotope effect has generally been attributed to the strength of the bond between anomeric carbon and the ring oxygen. An inverse effect is characteristic of an endocyclic cleavage, whereas a normal effect refers to the exocyclic cleavage. ${ }^{14}$ The values obtained for isopropyl and 4-nitrophenyl glycosides of $\alpha$-arabinofuranose (1a) are 0.987 and 1.023, respectively, ${ }^{15}$ and hence fully consistent with endocyclic and exocyclic cleavage, respectively. $\beta$-deuterium effect of 0.979 is also consistent with the endocyclic cleavage of the isopropyl acetal of $\alpha$-arabinofuranose.

\section{Acidic Hydrolysis of Alkyl and Aryl Pyranosides}

The hydrolysis of pyranosides has been more extensively studied than the hydrolysis of corresponding furanosides. ${ }^{5,6}$ The reactivity and the site of reaction have been widely discussed in terms of the theory of stereoelectronic control. ${ }^{16}$ According to the theory, an oxygen lone electron pair in antiperiplanar orientation with respect to the bond to be cleaved is required to 
ensure the optimal orbital overlap at the transition state where a double bond between anomeric carbon and an oxygen atom is being formed. Considering the geometry of pyranoside anomers, $\alpha$-anomers are expected to hydrolyse via exocyclic cleavage, whereas an endocyclic cleavage is predicted in the case of $\beta$-anomers. Unequivocal evidence for the endocyclic cleavage, particularly as the sole reaction pathway, has not been obtained. It has however been recognized that also the synperiplanar orientation allows the stereoelectronically controlled hydrolysis, thereby removing the need of endocyclic cleavage. ${ }^{17-19}$ There is, however, evidence that endocyclic cleavage of pyranosides may take place even in aqueous solutions, but it is believed to be a minor pathway. In contrast, under anhydrous conditions and in the presence of Lewis acid pyranosides react via the endocyclic pathway. ${ }^{20-24}$

\section{Isotope effects in the hydrolysis of pyranosides}

Values reported in the literature for various heavy atom isotope effects in hydrolysis of glycosides have been collected in Table 2. As mentioned in the previous chapter, ring and leaving group ${ }^{18} \mathrm{O}$ values reflect the double bond formation between the oxygen and anomeric carbon, and hence directly the structure of the oxocarbenium ion. The effect $\left({ }^{16} \mathrm{O} /{ }^{18} \mathrm{O}\right)$ is inverse, when the bond is being cleaved at the transition state. ${ }^{14,25}$ A normal effect reflects the increase in the double bond character. The values collected in the table show, hence, that in the case of pyranosides, under the experimental conditions, the cleavage is exocyclic and a cyclic oxocarbenium ion is formed, independent of the nature of the aglycon: a normal aglycon ${ }^{18} \mathrm{O}$ effect is observed both with aryl and alkyl aglycons. As was discussed above, and as can be seen from the results in Table 2, with furanosides the situation is different, and an inverse aglycon ${ }^{18} \mathrm{O}$ effect is observed for the hydrolysis of isopropyl- $\alpha$-arabinofuranoside, where other kinetic data is consistent with endocyclic cleavage.

Anomeric carbon ${ }^{13} \mathrm{C}, \alpha$-D and $\beta$-D effects are also collected in Table 2 . These values reflect the changes in bonds and hybridisation of anomeric carbon and the ring conformation, and hence also the site of the cleavage, but less directly. ${ }^{14}$ All the values shown in Table 2 are consistent with the exocyclic cleavage being the predominant pathway in the hydrolysis of pyranosides. 
Table 2. Isotope effect values (light / heavy) determined for the hydrolysis of glycosides

\begin{tabular}{|c|c|c|c|c|c|c|}
\hline Substrate & Ref. & Ring ${ }^{18} \mathrm{O}$ & Aglycon ${ }^{18} \mathrm{O}$ & ${ }^{13} \mathrm{C}(\mathrm{C} 1)$ & $\alpha-\mathrm{D}$ & $\beta-\mathrm{D}$ \\
\hline $\begin{array}{l}\text { Methyl } \alpha \text {-xylopyranoside (5a) } \\
\mathrm{HClO}_{4}, 80{ }^{\circ} \mathrm{C}\end{array}$ & 25 & 0.983 & 1.023 & 1.006 & 1.128 & 1.088 \\
\hline $\begin{array}{l}\text { Methyl } \beta \text {-xylopyranoside (5b) } \\
\mathrm{HClO}_{4}, 80{ }^{\circ} \mathrm{C}\end{array}$ & 25 & 0.978 & 1.023 & 1.006 & 1.098 & 1.042 \\
\hline $\begin{array}{l}\text { Methyl } \alpha \text {-glucopyranoside (7) } \\
\mathrm{HClO}_{4}, 80{ }^{\circ} \mathrm{C}\end{array}$ & 14,25 & 0.996 & 1.026 & 1.007 & 1.137 & 1.073 \\
\hline $\begin{array}{l}\text { Methyl } \beta \text {-glucopyranoside (6a) } \\
\mathrm{HClO}_{4}, 80{ }^{\circ} \mathrm{C}\end{array}$ & 14,25 & 0.991 & 1.024 & 1.011 & 1.089 & 1.045 \\
\hline $\begin{array}{l}p \text {-nitrophenyl } \beta \text {-glucopyranoside } \\
(\mathbf{6 b})\end{array}$ & 26 & & 1.023 & & & \\
\hline $2 \mathrm{M} \mathrm{HClO}_{4}, 75.1^{\circ} \mathrm{C}$ & & & & & & \\
\hline $\begin{array}{l}\text { Isopropyl } \quad \alpha \text {-arabinofuranoside } \\
(1 \mathrm{a} ; \mathrm{R}=\text { isopropyl) } \\
1.01 \mathrm{M} \mathrm{HClO}_{4}, 30.2^{\circ} \mathrm{C}\end{array}$ & 15 & & 0.988 & & & 0.979 \\
\hline $\begin{array}{l}p \text {-nitrophenyl } \\
\alpha \text {-arabinofuranoside (1a; } \mathrm{R}=p \text { - } \\
\text { nitrophenyl) } \\
0.098 \mathrm{M} \mathrm{HClO}_{4}, 80^{\circ} \mathrm{C}\end{array}$ & 15 & & 1.023 & & & \\
\hline
\end{tabular}

\section{Activation parameters}

Activation parameters of acid catalysed pyranoside hydrolysis are collected in Table 3 . As can be seen, the values of activation entropy for the hydrolysis of unsubstituted glycosides are invariably positive, consistent with an exocyclic cleavage that takes place by a unimolecular mechanism. The nature of the aglycon has little effect: the values for the hydrolysis of aryl glycosides are slightly smaller than corresponding values for the hydrolysis of alkyl glycosides, but still positive. The nature of an alkyl aglycon is not reflected in the activation entropy values either. In a series of alkyl glucosides the activation entropy values vary a little, but no trend is observed as in the case of alkyl furanosides. Included in Table 3 are the results obtained with a glycoside model 13 that reacts via both exocyclic and endocyclic pathways. The values shown are consistent with those reported for pyranosides and furanosides (Table 1). The activation entropy determined for the endocyclic cleavage is negative, whereas the exocyclic reaction is characterized by a positive $\Delta S^{\ddagger}$ value. ${ }^{27}$ As discussed in Chapter 2, the negative activation entropy values are not evident for the unimolecular endocyclic reaction. However, nucleophilic participation of the solvent at the transition state and the increasing rigidity of the molecule resulting from the formation of a double bond between the anomeric carbon and the exocyclic oxygen, have been offered as potential explanations. ${ }^{27}$ In contrast, positive activation entropy is easily attributable to a unimolecular reaction where two molecules are formed at the rate determining step. 
Xylopyranosides

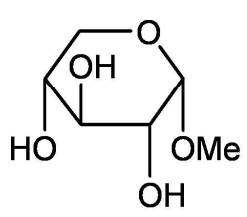

$5 \mathbf{a}$

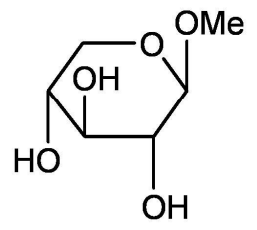

$5 b$

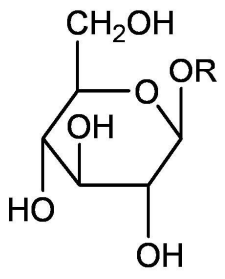

\section{Glucopyranosides}
6f: R=neopentyl
6g: $R=$ cyclohexyl
6h: $R=$ benzyl
6i: $R=$ phenyl
6a: R=methyl
6b: $\mathbf{R}=p$-nitrophenyl
6c: $R=$ isopropyl
6d: $R=$ butyl
6e: $R=i s o b u t y l$

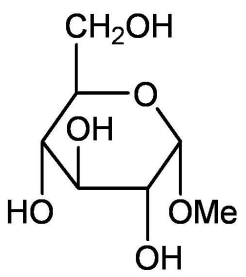

7

Galactopyranosides

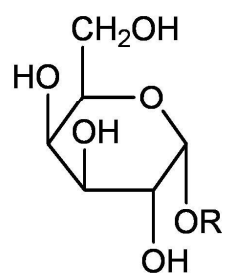

8a: $R=$ ethy $\mid$

8b: R=methyl

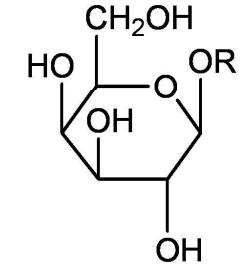

9a: $R=$ methyl

9b: R=phenyl

9c: $\mathrm{R}=p$-nitrophenyl
Mannopyranosides

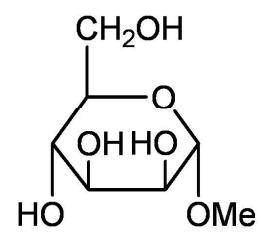

10

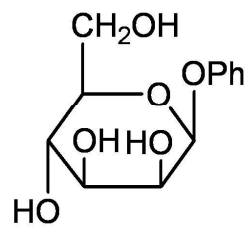

11
Allopyranoside<smiles>OCC1OC(c2ccccc2)C(O)C(O)C1O</smiles>

12

\section{Figure 2}

Activation enthalpies of the reactions of $\mathbf{1 3}$ may be slightly smaller than those of glycosides, but they show the same trend: values of 80.3 and $95.3 \mathrm{kJmol}^{-1}$ for endocyclic and exocyclic reaction, respectively, show that the endocyclic cleavage is enthalpically favoured. The higher $\Delta H^{*}$ for the hydrolysis of the exocyclic cleavage has been attributed to the strength of the exocyclic $\mathrm{C}-\mathrm{O}$-bond; in a $\beta$-glycoside electron donation from the exocyclic oxygen weakens the endocyclic bond. ${ }^{27}$ This explanation is supported by the data in Table 3, where it can be seen that values of $\Delta H^{*}$ for the reactions of $\beta$-anomers are generally more favourable than those for the reactions of corresponding $\alpha$-anomers

The activation entropy values for the hydrolysis of substrates bearing substituents in the glycoside ring, depend on the structure of the substrate. The values for the hydrolysis of fluorosubstituted glucosides are positive and of the same magnitude as the value for the hydrolysis of unsubstituted glucoside. In contrast, the hydrolysis of fluorosubstituted galactosides is characterized by negative activation entropy values. The authors have tentatively attributed this to more significant solvent reorganization at the transition state of the hydrolysis of galactosides. ${ }^{28}$ 
Table 3. Activation parameters for the hydrolysis of pyranosides. Values have been calculated on the basis of data at $60^{\circ}$ in Ref. 29 , unless otherwise indicated

\begin{tabular}{|c|c|c|}
\hline Substrate & $\Delta H^{\ddagger} / \mathrm{kJmol}^{-1}$ & $\Delta S^{\ddagger} / \mathrm{JK}^{-1} \mathrm{~mol}^{-1}$ \\
\hline \multirow[t]{2}{*}{ Methyl $\beta$-glucopyranoside (6ab) } & 135.9 & $68.0($ ref. 11) \\
\hline & & 44.3 \\
\hline Isopropyl $\beta$-glucopyranoside (6c) & 138.8 & 58.5 \\
\hline Butyl $\beta$-glucopyranoside (6d) & 140.4 & 59.8 \\
\hline Isobutyl $\beta$-glucopyranoside (6e) & 141.3 & 63.5 \\
\hline Neopentyl $\beta$-glucopyranoside (6f) & 150.5 & 95.7 \\
\hline Cyclohexyl $\beta$-glucopyranoside (6g) & 140.0 & 64.0 \\
\hline Benzyl $\beta$-glucopyranoside (6h) & 140.4 & 59.4 \\
\hline Phenyl $\beta$-glucopyranoside (6i) & & $45.2($ ref. 11$)$ \\
\hline Methyl $\alpha$-glucopyranoside (7) & 146.7 & 70.6 \\
\hline DNP $\beta$-glucopyranoside $(\mathbf{6 b})^{\mathbf{a}}$ & $117.8\left(37^{\circ} \mathrm{C}\right)$ & 33.8 (ref. 28) \\
\hline \multirow[t]{2}{*}{ Methyl $\alpha$-galactopyranoside (8b) } & 142.2 & 74.1 (ref. 11) \\
\hline & & 68.9 \\
\hline Ethyl $\alpha$-galactopyranoside (8a) & & 46.9 (ref. 11) \\
\hline \multirow[t]{2}{*}{ Methyl $\beta$-galactopyranoside (9a) } & 133.8 & 55.7 (Ref. 11) \\
\hline & & 50.2 \\
\hline Phenyl $\beta$-galactopyranoside (9b) & & 17.1 (ref. 11) \\
\hline DNP $\beta$-galactopyranoside $(\mathbf{9 c})^{\mathbf{a}}$ & $107.0\left(37^{\circ} \mathrm{C}\right)$ & 12.0 (ref. 28) \\
\hline \multirow[t]{2}{*}{ Methyl $\alpha$-mannopyranoside (10) } & 145.0 & 43.5 (ref. 11) \\
\hline & & 72.3 \\
\hline Phenyl $\beta$-mannopyranoside (11) & $105.9\left(37^{\circ} \mathrm{C}\right)$ & -18.0 (ref. 28) \\
\hline \multicolumn{3}{|l|}{ Methyl $\beta$-xylopyranoside (5b) } \\
\hline \multirow[t]{2}{*}{ Methyl $\alpha$-xylopyranoside (5a) } & 139.6 & $65.3($ ref. 11) \\
\hline & & 62.4 \\
\hline Phenyl $\beta$-allopyranoside (12) & $111.3\left(37^{\circ}\right)$ & 19.4 (ref. 28) \\
\hline \multirow[t]{2}{*}{ Glycoside model $13^{b}$} & 95.3 (exocyclic) & 15.5 (exocyclic) \\
\hline & 80.3 (endocyclic) & -52.7 (endocyclic) \\
\hline
\end{tabular}

${ }^{\mathrm{a}}$ DNP $=$ Dinitrophenyl ${ }^{\mathrm{b}}$ Values refer to acid-catalysed methanolysis. Data from ref. 27.

\section{Analysis of the reaction intermediates}

The site of the initial cleavage in the reactions of glycosides has been studied also by gathering information on the structure of the reaction intermediates. Trapping of intermediates formed in hydrolysis of glycoside models in anhydrous solutions have shown that under the experimental conditions employed, the endocyclic cleavage is a significant reaction pathway. McPhail et al. ${ }^{22}$ showed that $\mathrm{FeCl}_{3}$ catalysed acetolysis of glycopyranosides proceeds via both endocyclic and exocyclic reaction pathways, and that the ratio of the reactions depends on the anomeric 
configuration of the substrate. The main pathway in the acetolysis of $\alpha$-glycosides involves the cyclic intermediate; $91 \%$ of the products observed are formed via the cyclic oxocarbenium intermediate. In contrast, an endocyclic reaction through an acyclic intermediate is favoured in the reaction of $\beta$-glycosides. The proportion of exocyclic and endocyclic reaction is approximately 1:3. An approximately even proportion of exocyclic and endocyclic reactions was observed in the acid-catalysed cleavage of tetrahydropyranyl acetal in anhydrous methanol using an intramolecular nucleophile to trap the intermediates. ${ }^{30}$

More recent studies in aqueous solutions have shown that the endocyclic reaction pathway is followed also in hydrolysis reaction, but it appears to be a minor route, and only observed with $\beta$-anomers. Anslyn et al. ${ }^{27,31}$ studied the structure of the intermediate using a model acetal containing an intramolecular nucleophile. As shown in Scheme 2, acyclic oxocarbenium intermediate formed as a result of endocyclic cleavage can be trapped by protiated or deuterated hydroxymethyl group and revert back to the starting material 13 or its deuterated congener 14. Alternatively, the acyclic intermediate may react with intermolecular nucleophile and cyclise in an intramolecular reaction, again using either the protiated or deuterated hydroxymethyl group. Reaction involving the protiated hydroxymethyl group gives products $\mathbf{1 5 a}$ and $\mathbf{1 5 b}$, whereas $\mathbf{1 6 a}$ and $\mathbf{1 6 b}$ are formed if the deuterated hydroxymethyl is involved. The endocyclic reaction can, hence, be observed in unreacted starting material, in appearance of $\mathbf{1 4}$ or in formation of products $\mathbf{1 6 a}$ and $\mathbf{1 6 b}$, assuming that the products are stable under the experimental conditions.

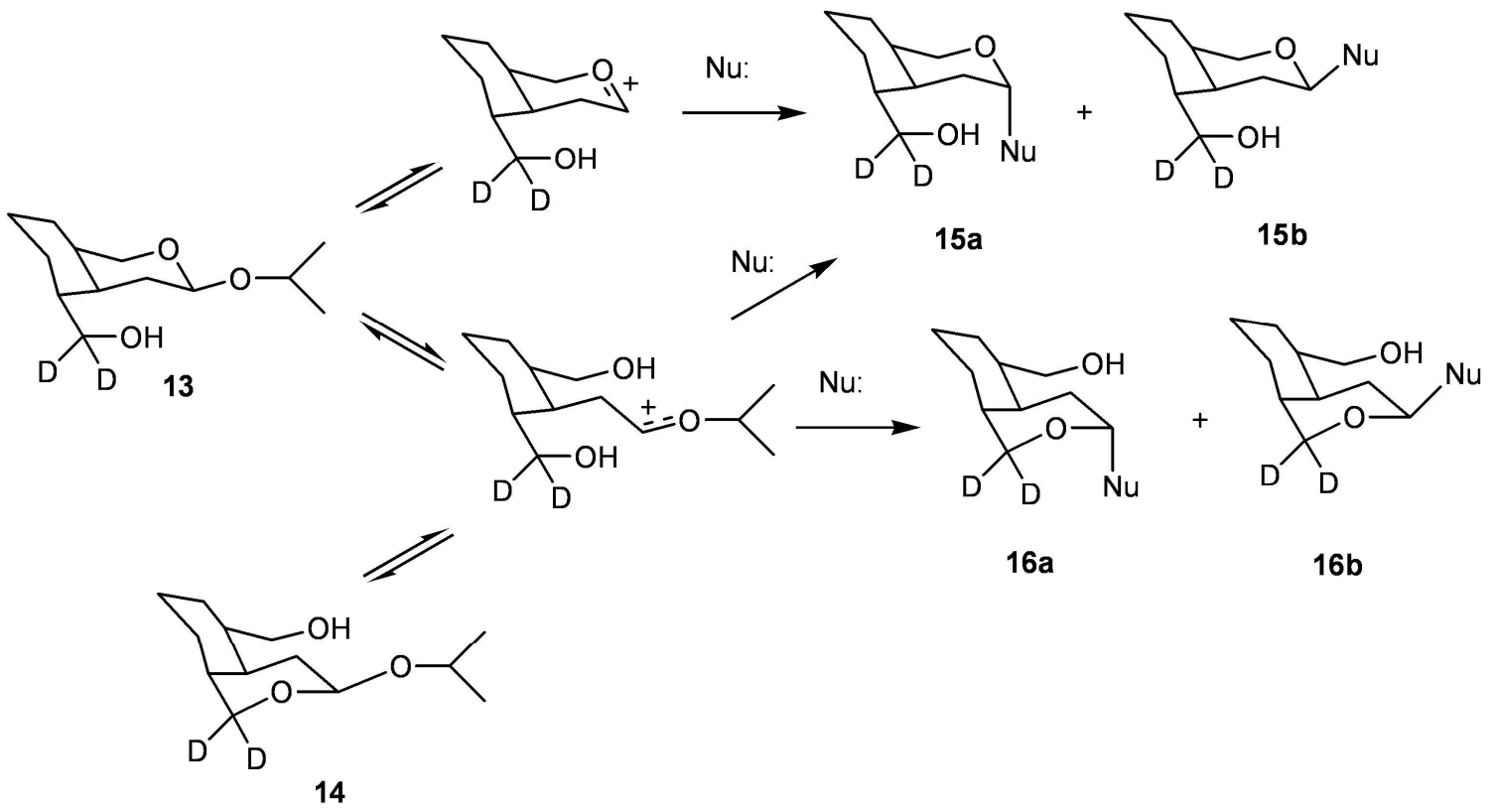

\section{Scheme 2}

The hydrolysis reaction of $\mathbf{1 3}$ results in a formation of an unstable hemiacetal, and hence the proportion of the endocyclic reaction was determined on the basis of the formation of the D- 
analogue 14 of the starting material. It was concluded that the proportion of the endocyclic reaction of the $\beta$-anomer is more than $12 \%$ at an ambient temperature. ${ }^{27}$ In methanolysis reaction the endocyclic reaction can be detected also in the products as acetals $16 \mathbf{a}$ and $\mathbf{1 6} \mathbf{b}$ are stable under the experimental conditions. The proportion in methanol appears to be smaller than in water, and clearly smaller than observed in the earlier studies of Franck ${ }^{30}$ and McPhail ${ }^{22}$. The proportion is $13 \%$ at $10{ }^{\circ} \mathrm{C}$ and increases as the temperature decreases. At $-30{ }^{\circ} \mathrm{C}$ the proportion is $31 \%$. In the reaction of the $\alpha$-anomer the proportion of the endocyclic reaction was negligible. This has also been predicted by theoretical calculations that show that in the case of the $\alpha$ anomer the acyclic intermediate is more unstable than the cyclic one by $7.3 \mathrm{kJmol}^{-1}{ }^{32}$

\section{Discussion}

It seems clear that the proportions of endocyclic and exocyclic cleavage in hydrolysis of furanosides and pyranosides are different. The kinetic data collected in Table 1, values for activation entropy and aglycon effects, together with solvent effects, show that in the case of furanosides, either pathway may be followed, depending on the structure of the substrate and reaction conditions. The comparison of isotope effect values for furanoside and pyranoside cleavage lends further support to the mechanistic conclusions. As discussed above, the interpretation of negative activation entropies observed is not quite straightforward and different explanations have been offered. The consistency of the experimental evidence suggests, however, that within a series of similar type of substrates, the sense of activation entropy may be safely used as an indicator of the predominant reaction mechanism, negative values referring to endocyclic, unimolecular reactions.

The kinetic evidence collected in Table 1 show, hence, that the more electronegative the aglycon moiety is, the higher is the proportion of the exocyclic reaction in the hydrolysis of furanosides. Electropositive aglycons, in contrast, favour the endocyclic pathway proceeding through an acyclic intermediate. The relationship is not, however, straightforward, but depends also on the structure of the glycon moiety. $\beta$-ribofuranosides $\mathbf{3 b}$ show the strongest tendency for endocyclic cleavage, while $\alpha$-arabinofuranosides 1a even with electropositive aglycons react via the exocyclic pathway. $\alpha$-ribofuranosides 3a and -arabinofuranosides 1a show a slightly more pronounced tendency towards exocyclic cleavage than their $\beta$-anomers, but in general there does not seem to be a clear correlation between the anomeric configuration of furanosides and the site of the initial cleavage.

It is equally clear that the hydrolysis of pyranosides proceeds predominantly through a cyclic intermediate. Positive activation entropies and various isotope effect values support this mechanism. The fact that the rate of the hydrolysis is rather insensitive to the nature of the aglycon, as shown by the results collected in Table 2, further supports the exocyclic cleavage as a predominant reaction pathway. The trapping experiments show, however, that a minor pathway involving an endocyclic cleavage, may accompany the exocyclic cleavage, at least in the case of 
$\beta$-glycosides. The proportion of the endocyclic cleavage may be so low that it is not reflected, to any significant extent, in activation parameters or isotope effect values.

The negative values for activation entropy show that the endocylic cleavage is an entropically unfavourable process, whereas the entropy term for the exocyclic cleavage, resulting in a formation of two products, favours the reaction. The enthalpy term is, however, more favourable in endocyclic than in the exocyclic reaction. As shown by the values collected in Table 1, reactions of isopropyl furanosides that are believed to react exclusively via the endocyclic pathway, are characterized by values of 80 to $95 \mathrm{kJmol}^{-1}$. Values for the reactions of substrates with more electronegative aglycons, where the exocyclic pathway predominates, range from 100 to $110 \mathrm{kJmol}^{-1}$. Values for the hydrolysis of pyranosides, which, as discussed above, react predominantly via the exocyclic pathway, are even higher ranging from 130 to $145 \mathrm{kJmol}^{-1}$. The net effect of the two factors is that the reactions of furanosides are generally faster than the reactions of pyranosides.

There are several factors that have been proposed to influence the reactivity of glycosides. Inductive effects of ring substituents destabilizing strongly the oxocarbenium ion, retard the hydrolysis. ${ }^{29}$ Glycosides are therefore less reactive than model acetals employed, as the hydroxyl groups on the glycon ring destabilize the oxocarbenium ion by withdrawing electrons from the cationic intermediate. The effect of axial ligands is believed to be more significant than that of equatorial ones. The rate retarding effects of hydroxy groups was originally explained by steric factors, but more recent studies have shown that there is no correlation between the reactivity and the size of the substituent. ${ }^{33}$ In contrast, a correlation has been observed between the reactivity and electronegativity of ring substituents. ${ }^{24}$

In the case of furanosides the sugar ring configuration correlates more clearly with the reactivity. The substituents of adjacent carbon atoms in cis orientation can be expected to repel each other, and this repulsion is relieved as the sugar ring is opened and an acyclic oxocarbenium ion is formed. The slow reactions of $\alpha$-arabinofuranosides 1a can hence be attributed to all-trans orientation of the ligands where the strain is less significant. As $\alpha$-arabinofuranosides are predominantly cleaved via the exocyclic pathway, it can also be proposed that the relief of strain is the driving force of endocyclic reactions. Relatively unstrained molecules react via the exocyclic pathway that is entropically favoured. Strained molecules, in contrast, react via the endocyclic pathway and the relief is observed as a higher reactivity and lower activation enthalpy values. On this basis, pyranosides, where the ring is nearly free of strain, are not expected to hydrolyse via the endocyclic pathway to any significant extent, unless ring strain is induced, for example by bulky substituents that strongly repel each other. The reasoning applies, however, for reactions in aqueous solutions only. As discussed above, the reactions under anhydrous conditions proceed rather via the endocyclic pathway.

The conclusion of this analysis is that while the hydrolysis involving endocyclic and exocyclic cleavage is possible with both furanosides and pyranosides, the endocyclic reaction is clearly less probable with pyranosides. The detection of the endocyclic reaction and estimation of the proportions of the two reaction pathways is, however, quite complicated, since there are 
several factors that may alter the situation. Any attempt to design a system where the oxocarbenium intermediate is trapped by an intramolecular nucleophile leads inevitably to structural changes that may influence reactivity and reaction mechanism, as is seen in the case of furanosides. Therefore, results obtained with model systems may not always be directly attributable to glycoside hydrolysis. On the other hand, the proportion of endocyclic cleavage of model system 13 has been shown to depend on temperature - which is also in consistence with the tendency of greater activation energies being observed for the exocyclic reactions. Therefore results obtained with certain glycoside at an elevated temperature may fail to show the endocyclic reaction. Solvent influences the proportion of the endocyclic reaction, as well. The cleavage of an endocyclic C-O -bond has been observed in many reactions of pyranosides under anhydrous conditions. ${ }^{34,35}$ As the environment in the active site of an enzyme may be hydrophobic, and hence resemble more organic solvent than water, reaction pathways observed in aqueous solutions may not apply to enzymatic reactions at all.

\section{References}

1. (a) Armstrong, E. F.; Caldwell, E. F. Proc. Roy. Soc. (London) 1904, 73, 526. (b) Armstrong, E. F.; Caldwell, E. F. Proc. Roy. Soc. (London) 1904, 74, 184. (c) Armstrong, E. F. Proc. Roy. Soc. (London) 1904, 74, 188. (d) Fischer, E.; Strauss, H. Ber. Dtsch. Chem. Ges. 1912, 2467.

2. Lönnberg, H. Mechanisms for the Cleavage of the Glycosidic Linkage in the Hydrolytic Decomposition of Aldofuranosides, Ph.D. Thesis, University of Turku, 1976.

3. (a) Lönnberg, H.; Kankaanperä, A.; Haapakka, K. Carbohydrate Research, 1977, 56, 277. (b) Lönnberg, H.; Kulonpää, A. Acta Chem. Scand. 1977, A31, 306. (c) Lönnberg, H.; Arminen, M. Finn. Chem. Lett. 1978, 244. (d) Lönnberg, H.; Valtonen, L. Finn. Chem. Lett. 1978, 209.

(e) Lönnberg, H.; Vesala, A. Carbohydrate Res. 1980, 78, 53. (f) Vesala, A.; Lönnberg, H.; Kappi, R.; Arpalahti, J. Carbohydrate Res. 1982, 102, 312. (g) Lönnberg, H.: Gylen, O. J. Carbohydrate Chem. 1983, 2, 177.

4. For a review, see: Oivanen, M.; Hovinen, J.; Lehikoinen, P.; Lönnberg, H. Trends Org. Chem. 1993, 4, 397.

5. Capon, B. Chem. Rev. 1969, 69, 407.

6. Berti, P. J.; Tanaka, K. S. E. Adv. Phys. Org. Chem. 2002, 37, 239.

7. Horenstein, N. A. Adv. Phys. Org. Chem. 2006, 41, 275.

8. Mohr, M.; Bryce, R.A.; Hillier, I. H. J. Phys. Chem. A 2001, 105, 8216.

9. (a) Zechel, D. L.; Withers, S. G. Acc. Chem. Res. 2000, 33, 11. (b) Lillelund, V. H.; Jensen, H. H.; Liang, X.; Bols, M. Chem. Res. 2002, 102, 515.

10. (a) Kirby, A. J. Nature Struct. Biol. 2001, 8, 737. (b) Bottoni, A.; Miscione, G. P.; De Vivo, M. PROTEINS: Structure, Function and Bioinformatics 2005, 59, 118.

11. Isaacs, N. S.; Javaid, K.; Capon, B. J. Chem. Soc., Perkin Trans.II 1982, 101. 
12. (a) Salomaa, P.; Kankaanperä, A. Acta Chem. Scand. 1961, 15, 871. (b) Fife, T.H.; Jao, L. K. J. Org. Chem. 1965, 30, 1492. (c) Fife, T. H.; Hagopian, L. J.Org. Chem. 1966, 31, 1772

13. (a) Wolford, R. K. J. Phys. Chem. 1964, 68, 3392. (b) Cox, B. G.; McTigue, P. T. Aust. J. Chem. 1967, 20, 1815. (c) McTigue, P. T.; Watkins, A. R. Aust. J. Chem. 1972, 25, 777

14. Bennet, A. J.; Sinnot, M. L. J. Am. Chem. Soc. 1986, 108, 7278.

15. Bennet, A. J.; Sinnot, M. L.; Wijesundera, W. S. S. J. Chem. Soc., Perkin Trans.II 1985, 1233.

16. Sinnott, M. L. Adv. Phys. Org. Chem. 1988, 24, 113.

17. Andrews, C. W.; Bowen, J. P.; Fraser-Reid, B. J. Chem. Soc., Chem. Commun. 1989, 1913.

18. Li, S.; Kirby, A. J.; Deslongchamps, P. Tetrahedron Lett. 1993, 34, 7757.

19. Fraser-Reid, B.; Merrit, J. R.; Handlon, A. L.; Andrews, C. W. Pure \& Appl. Chem. 1993, $65,779$.

20. Lichtenthaler, F. W.; Breunig, J.; Fischer, W. Tetrahedron Lett. 1971, 30, 2825.

21. Guindon, Y.; Anderson, P. C. Tetrahedron Lett. 1987, 28, 2485.

22. McPhail, D.R.; Lee, J.R.; Fraser-Reid, B. J. Am. Chem. Soc. 1992, 114, 1905.

23. Olsson, R.; Berg, U.; Frejd, T. Tetrahedron 1998, 54, 3935.

24. Jensen, H. H.; Lyngbye, L.; Bols, M. Angew. Chem. Int. Ed. 2001, 40, 3447.

25. Induragalla, D.; Bennet, A. J. J. Am. Chem. Soc. 2001, 123, 10889.

26. Bennet, A. J.; Davis, A. J.; Hosie, L.; Sinnot, M .L. J. Chem. Soc. Perkin Trans. II 1987, 581.

27. Liras, J. L.; Lynch, V. M., Anslyn, E. V. J. Am. Chem. Soc. 1997, 119, 8191.

28. Namchuk, M. N.; McCarter, J. D.; Becalski, A.; Andrews, T.; Withers, S. G. J. Am. Chem. Soc. 2000, 122, 1270.

29. (a) Timell, T. E. Can. J. Chem. 1964, 42, 1456. (b) Timell, T. E.; Enterman, W.; Spencer, F.; Soltes, E. J. Can. J. Chem. 1965, 43, 2296.

30. Gupta, R. B.; Franck, R. W. J. Am. Chem. Soc. 1987, 109, 6554.

31. Liras, J. L.; Anslyn, E. V. J. Am. Chem. Soc. 1994, 116, 2465.

32. Deslongchamps, P.; Li, S.; Dory, Y. L. Org. Lett. 2004, 6, 505.

33. Helligso, H.: Jensen, H. H.; Bols, M. Org. Lett. 2003, 5, 3419.

34. Johansson, K-J.; Konradsson, P.; Trumpakaj, Z. Carbohydrate Res. 2001, 332, 33.

35. Kaczmarek, J.; Kaczynski, Z.; Trumpakaj, Z.; Szafranek, J.; Bogalecka, M.; Lönnberg, H. Carbohydrate Res. 2000, 325, 16. 